MATEC Web of Conferences 3, 01069 (2013)

DOI: $10.1051 /$ matecconf/20130301069

(c) Owned by the authors, published by EDP Sciences, 2013

\title{
Stable, metastable and unstable phases of halogen methane derivatives
}

\author{
J.Ll. Tamarit \\ Grup de Caracterització de Materials, Department de Física I Enginyeria Nuclear, ETSEIB, Diagonal 647, 08028 Barcelona, \\ Universitat Politècnica de Catalunya, Catalonia
}

\begin{abstract}
Many molecular materials composed of globular or pseudoglobular molecules are capable of forming hightemperature orientationally disordered (OD) phases in which long-range positional order exists and orientational order has been lost. Halogen methane derivatives, as tetrahalogenomethane compounds $\left(\mathrm{CX}_{\mathrm{n}} \mathrm{Y}_{\mathrm{m}}\right.$, where $\mathrm{n}$ and $\mathrm{m}$ $=0, \ldots, 4 ; \mathrm{n}+\mathrm{m}=4$, and $\mathrm{X}, \mathrm{Y}=\mathrm{F}, \mathrm{Cl}, \mathrm{Br}$ and $\mathrm{I}$ ) have been investigated by the Group of Characterization of Materials at the Universitat Politècnica de Catalunya during the last years [1]. In spite of the similarity of the molecules, fine tuning interactions give rise to a polymorphic behavior at normal pressure, i.e. in equilibrium with its vapor, quite different. The rational of the thermodynamics can be achieved when the polymorphism is analyzed in the whole temperature-pressure space. The presentation will describe the stable and metastable phases of those compounds revealed by the uncommon inclusion of the pressure variable as well as by the analyses of the two-component systems sharing them. Moreover, the emergence of unstable phases (glasses) [2] within the low-temperature domain will be analyzed and the similarities with the canonical glassformers will be discussed.
\end{abstract}

\section{References}

1. M. Barrio et al. J. Phys. Chem. B 1151679 (2011); Chem. Phys. 358156 (2009); New J. Chem. 32(2) 232 (2008); J. Phys. Chem. B 1118899 (2007); J. Phys. Chem. B 108, 11089 (2004); Sz. Pothoczki et al. Phys. Rev. B 85014202 (2012); Ph. Negrier et al., Cryst. Growth and Design 102793 (2010); Chem. Phys. 336150 (2007): R. Levit et al. J. Phys. Chem. B, 112 13916 (2008); J.Ll. Tamarit et al. J. Phys. Cond. Matter 20244110 (2008); B. Parat et al., Chem. Mater. 173359 (2005); L.C. Pardo et al. Chem. Phys. Lett. 402408 (2005); Phys. Rev. B 72014206 (2005); N. Veglio et al. Phys. Rev. E 72031502 (2005)

2. M.J. Zuriaga et al. J. Chem. Phys. 137054506 (2012); Phys. Rev. Lett. 103075701 (2009) 